At a meeting of the Editorial Committee held on 2 November 1982 some of the matters discussed would, I thought, be of interest to readers of the Journal.

\section{Delays in publication}

This is a perennial problem, but Dr Stephen Lock, Editor of the British Medical Journal, was not concerned that for a bi-monthly journal the average wait was around $9 \frac{1}{2}$ months. The Journal had received 167 papers in the year, an increase of $16.7 \%$ over the previous 12 months, and there were papers in hand sufficient for the December 1982 and the February and April 1983 issues. Nevertheless, several members of the Committee were concerned at the delay since they felt that it might deter potential authors from submitting papers to the Journal. Suggestions were made for cutting the delay, including the abolition of refereeing, eliminating some stages in the printing process, and giving priority to important papers. The Editor noted that this last was already done, but it was agreed that an announcement should be published stating that a mechanism existed for expediting papers and that authors could plead their case if they felt their paper warranted early publication. It was also agreed that the date of acceptance of a paper as well as the date of receipt should be published.

\section{Avoiding fuddy-duddiness}

There were some interesting views here. One member thought that we should try and keep up with molecular biology and hoped that papers on this discipline would be forthcoming. Another felt that since the Journal was intended mainly for clinical geneticists we were likely only to get 'cast-offs' on molecular biology. The Editor feels that such polarisation is not inevitable and that review articles on molecular genetics might help to solve the problem.

\section{Review articles}

The numbers, though not the quality, here have been disappointing. It was felt that a greater effort should be made to obtain papers from younger authors, and it was agreed to approach heads of clinical genetics units with this in view. An increase of the fee to $£ 75$ might make the proposition more attractive. The Editor felt that it would increase the interest in the Journal if some of the views were speculative, for example on maternal inheritance or 'risk factors', and that on the experimental side topics such as the fragile $X$, aneuploidy, or preventing congenital abnormalities would be very suitable.

\section{Association with Societies}

It was generally agreed that the Journal should not be the mouthpiece of either the Clinical Genetics Society or the Association of Clinical Cytogeneticists, though friendly relations with both should be maintained, and the Editor felt that the publication of abstracts of meetings had been a useful exercise. It was agreed that each of the Societies should nominate a member to the Editorial Committee.

\section{Human gene mapping nomenclature}

At the meeting in May 1980 a new nomenclature for human gene mapping was discussed, but it was decided not to adopt this. At the meeting on 2 November 1982 the subject was reopened and later Dr Bodmer wrote that his quibbles with the new nomenclature had related to his own pet (HLA) system because of changes which were in contradiction to the then accepted international nomenclature. His criticisms were noted and he now thinks the amended proposals are good and worth following. The Editor therefore thinks that we should accept the new nomenclature.

\section{'Lateral reading'}

Some years ago the Editor had suggested that readers should send in extracts of interest from other journals, but this idea had never properly got off the ground. It was now felt that the Editor should be in charge of such a column, which might be designated 'Lateral reading'. He would keep a look out for items himself but would also welcome contributions. The following examples will show how he spent his Christmas.

CANCER AND imMORTALity (see Newbold RF, Overell RW, Connell JR. Nature 1982;299:633-5)

Limited lifespan in normal diploid mammalian cells in culture is well recognised, whereas cells derived from malignant tissue often appear to be immortal. Newbold et al have carried out experiments with Syrian hamster cell cultures and the results suggest that normal mammalian cells can be induced to 
escape from their commitment to senescence. This is effected by exposing them to various mutagenic carcinogens, though the resulting capacity for infinite multiplication precedes (and may be necessary for) malignant transformation. I recall J B S Haldane's poem "Cancer is a funny thing".

PRESENILE CATARACT (see Winder AF. Trans Ophthalmol Soc UK 1981 ;101:127-30)

Various studies have shown that presenile cataract may be caused by the heterozygous state for galactokinase deficiency, but the above is the first paper, as far as Dr Sarah Bundey knows, which describes the risk for offspring of heterozygous mothers. Earlier observations have confirmed that among patients with presenile cataracts there is an excess of heterozygotes for galactokinase and galactose-1-phosphate uridyl transferase deficiency, over what one would expect from the population frequencies. It is clearly important to consider these biochemical states in persons with presenile cataracts, but particularly so if the patient is a woman of childbearing years. It had earlier been observed that mothers of children with infantile cataracts had a lowered distribution of galactokinase levels compared to controls and in 1981 specific examples were reported by Winder. He described four families where mothers heterozygous for galactokinase deficiency (but only recognised as such after the births of their affected children) had children with congenital cataracts. The size of the risk for this occurring in the offspring of heterozygous women cannot be judged from Winder's paper. However, it is likely that these cataracts are preventable and so ophthalmologists should be on the look out for galactokinase heterozygotes who present either with presenile cataracts or with a child with congenital cataracts. The cataracts associated with galactokinase deficiency are thought to be the result of a direct effect on the lens of galactose and galactitol, and the cataracts resulting from deficiency of galactose-1-phosphate uridyl transferase are also the result of high levels of galactose-1-phosphate on the lens. However, the latter substance does not cross the placenta. Women who are deficient in either of these two enzymes should be kept on a restricted galactose diet during any pregnancy.

ERRORS IN THE DIAGNOSIS OF CYSTIC FIBROSIS (see David TJ, Phillips BM. Lancet 1982;ii:1204-6)

In seven patients seen over 3 years, cystic fibrosis had been wrongly diagnosed. The initial sweat test was misleadingly high in only three cases. In one case no sweat test had been done, and in four, one or more normal sweat test results were ignored. As a result of misdiagnosis four children were sent to schools for the physically handicapped and one man lost his job in the police. Despite warnings about the limitations of sweat tests and dangers of diagnosing cystic fibrosis without typical clinical features, cystic fibrosis is wrongly diagnosed in substantial numbers of children in England.

DUPUYTREN'S CONTRACTURE (see Ling RSM. J Bone Joint Surg [Br] 1963;45:709-18)

For some years $I$ have been interested in the inheritance of this condition but have only recently seen the paper by Ling, from which there seems no doubt that the disorder is usually controlled by an autosomal dominant gene. In two of Ling's pedigrees the probands had parents both of whom were affected, and therefore their offspring may have been homozygotes; a point in favour of this is that both probands had severe lesions. I have asked Mr Ling if he can update the pedigrees as, if homozygosity is present in the cases be cites, then all the children should be affected in the next generation. In his article Ling makes no mention of the disorder affecting the feet, but in my experience it may do so, producing 'lumps' which I think are thickened tendon sheaths, though there is no deformity. Lack of examination of the feet may result in underdiagnosis in relatives of those affected.

BLADDER CANCER AND MOLECULAR GENETICS (see Logan J, Cairns J. Nature 1982;300:104-5; Tabin CJ, et al, ibid 143-9; Reddy EP, et al, ibid 149-52)

In the issue of Nature of 11 November 1982 there are two papers and a leader on the way in which cells, and particularly human bladder cells, may become malignant. In general, carcinogenesis is thought to be a multi-step process and one of the first stages may be the activation of a cellular gene whose function usually has nothing to do with cancer but with normal embryonic development. Various factors, for example viral infections, a chance mutation, or an environmental effect, may convert the proto- into an oncogene. The important development is that the oncogenes can be identified by certain retroviruses, that is, those whose genome can exist in both RNA and DNA forms. The oncogene of one line (EJ) of human bladder carcinoma cells has now been identified by the retrovirus technique as differing from the normal by the alteration of one nucleotide, and this single mutation may well have been environmentally determined (knowing of the occupational hazards in bladder cancer). In another line of human bladder carcinoma (T24) the protooncogene is also activated by a single amino-acid 
substitution. We are therefore getting close to the molecular basis of malignancy. But why not carry out the reverse experiment to test the hypothesis? Carcinoma of the oesophagus is sure to occur in certain persons who suffer from tylosis (Howel Evans et al. $Q J$ Med 1958;27:413). Can one not work backwards to show how these persons differ molecularly from their non-tylotic sibs? Every time I ask this question the reply is: "We are not working on this".

ATTITUDES OF THOSE AT RISK FOR HUNTINGTON'S DISEASE TOWARDS PRESYMPTOMATIC PROVOCATIVE TESTING (see McCormack MK, Lazzarini A. N Engl J Med 1982;307:1406)

In a letter, the authors raise again the already well- ventilated problem of whether or not people at risk for Huntington's chorea wish to know what the future holds. Of 40 well-informed subjects from affected families, 16 were willing to be tested with levodopa, knowing that there was the risk of transient choreic movements, and a further five wished to know the truth provided there was no risk of transient choreic movement. The authors feel that those at risk for Huntington's chorea are far more receptive to provocative testing than perhaps their physicians or even researchers have realised. This is all very well, but about half the subjects thought exactly the opposite. What do readers feel, and how reliable is the levodopa test? 